\title{
Gamify - A Gamified Assessment Model
}

\author{
Mr. Yuvraj N N, Chetan Jawale, Ankita Kolhe, Akanksha Kaygude \\ Department of Computer Engineering, DYPSOEA, Savitribai Phule Pune University, India
}

\begin{abstract}
Gamification of assessment is a developing approach for increasing motivation and engagement of learner's by integrating game design elements in educational/assessment environments. With the growing popularity of gamification and the mixed success of its application in educational environments, the current review is aiming to shed a more realistic light on the research in this field by focusing on empirical evidence rather than on potentialities, beliefs or fondness. Accordingly, it thoroughly examines the advancement in gamifying the assessment. The discussion is structured around the used gamification mechanisms, the gamified subjects, types of gamified activities in assessing candidates, and the study goals, stressing on the reliability and validity of the reported outcomes
\end{abstract}

Keywords: Assessment, Engagement, Formative Assessment, Gamification, Gamifying Assessment, Learning, Performance, Students Motivation.

\section{INTRODUCTION}

Gamification of assessment is the process of adding game, elements throughout the learning, recruitment, selection process, in order to make it alluring and easy to use, thereby increasing the engagement and motivation of the candidates undertake the assessment. Gamification is a term that has become increasingly widespread in today's world. It uses game design elements to create the environment for the gamified experiences. Gamification typically means adding game-like aspects such as badges, points, and rules. For example, every time you visit the store and swipe your rewards card, that is gamification. The store is rewarding you with discounts, points and free stuff because you are carrying out the coveted action when you make a purchase.

\section{LITERATURE Survey}

In brief, in studies in the literature about gamified assessment only scoring, feedback and leaderboard features were used together (Cheong, Cheong, \& Filippou, op. cit.; Wang, op. cit.) and assessment processes were designed only to grade certain tasks (Moccozet et al., 2013). None of the studies in the literature provide information about how to gamify an assessment. Also the potential effects of gamified assessment were not determined by any research. This study was conducted considering this lack of studies in the literature. A gamified assessment environment was designed on a theoretical basis and implemented. Student opinions about this gamified assessment were determined. GAMED: GamificationBased Assessment Methodology for Final Project Development by Paulo Silas Severo de Souza, Jaline Gonçalves Mombach, Fábio Diniz Rossi, and Tiago Coelho Ferreto describe Teachers and psychologists report that students may suffer from multiple psychological issues such as lack of interest and high levels of stress during the development of final course projects. In this context, approaches such as gamification arise with the proposal of improving student's motivation by bringing games elements to school. However, employing gamification into classroom is not a trivial task since, if not managed properly, students may lose their focus. In this paper we present GAMED, an assessment methodology that introduces systematic steps to improve students engagement through gamification. We used GAMED in a class with high school students during two semesters and the results showed that it can improve aspects such as motivation, engagement, and teamwork.

\section{PROPOSED WORK}

There is an increased demand of assessment platforms due to current situations. The Student is connected to the platform through internet. He/she may assess themselves using the application.

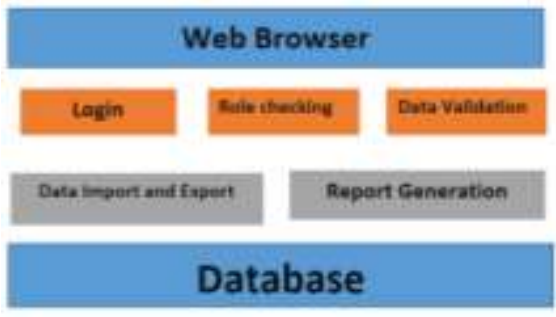




\section{International Advanced Research Journal in Science, Engineering and Technology}

Vol. 8, Issue 6, June 2021

\section{DOI: $10.17148 / I A R J S E T .2021 .8605$}

Examiner has the ability to view user information and even check the users test process. Admins have control over both Students and Examiners.

\section{MOTIVATION}

The web enabled application can be accessed from anywhere through the internet. It will be helpful as the students can use it whenever he/she feels like it. The system will be able to take care of the students records in a quick manner. Students will be able to see their result right after giving the examination. This system supports MCQ, Fill in the Blanks and Subjective questions. At present many companies are following this type of automatic assessment for aptitude test in placement.

\section{METHODOLOGY}

GAMED consists of a novel methodology that brings to the course curriculum a set of activities based on concepts of gamification and formative assessment to improve students motivation and engagement. Keeping in mind the students' issues presented in Section II, we designed GAMED with four main phases

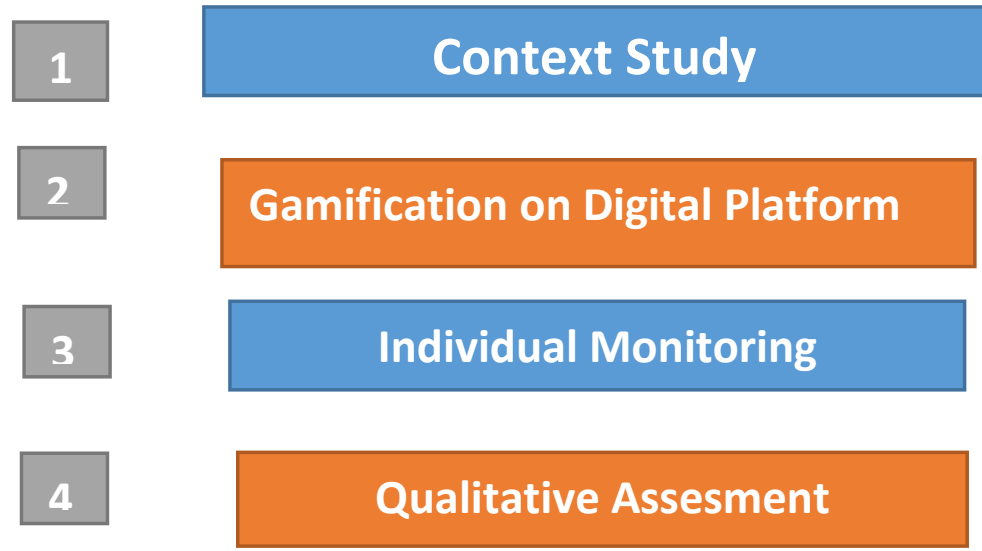

VI. RESULT

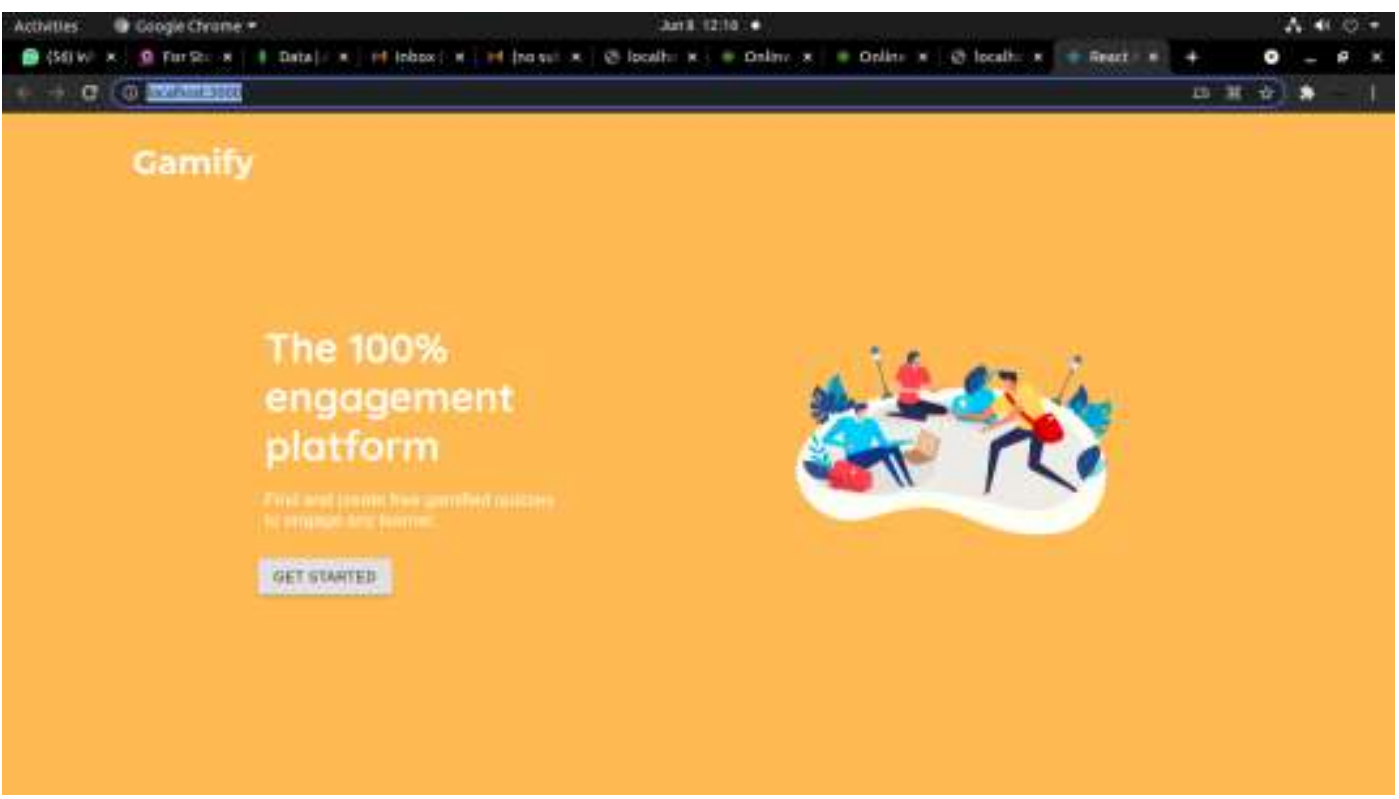

Fig .Landing Page 
DOI: $10.17148 /$ IARJSET.2021.8605
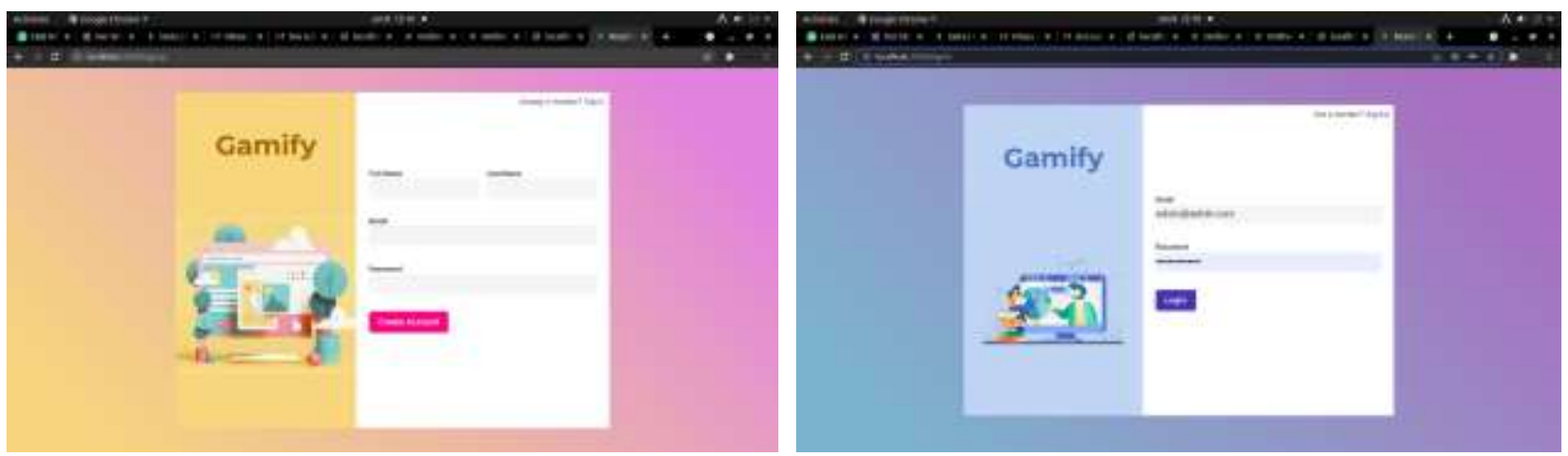

Fig. Resiger and Login Page
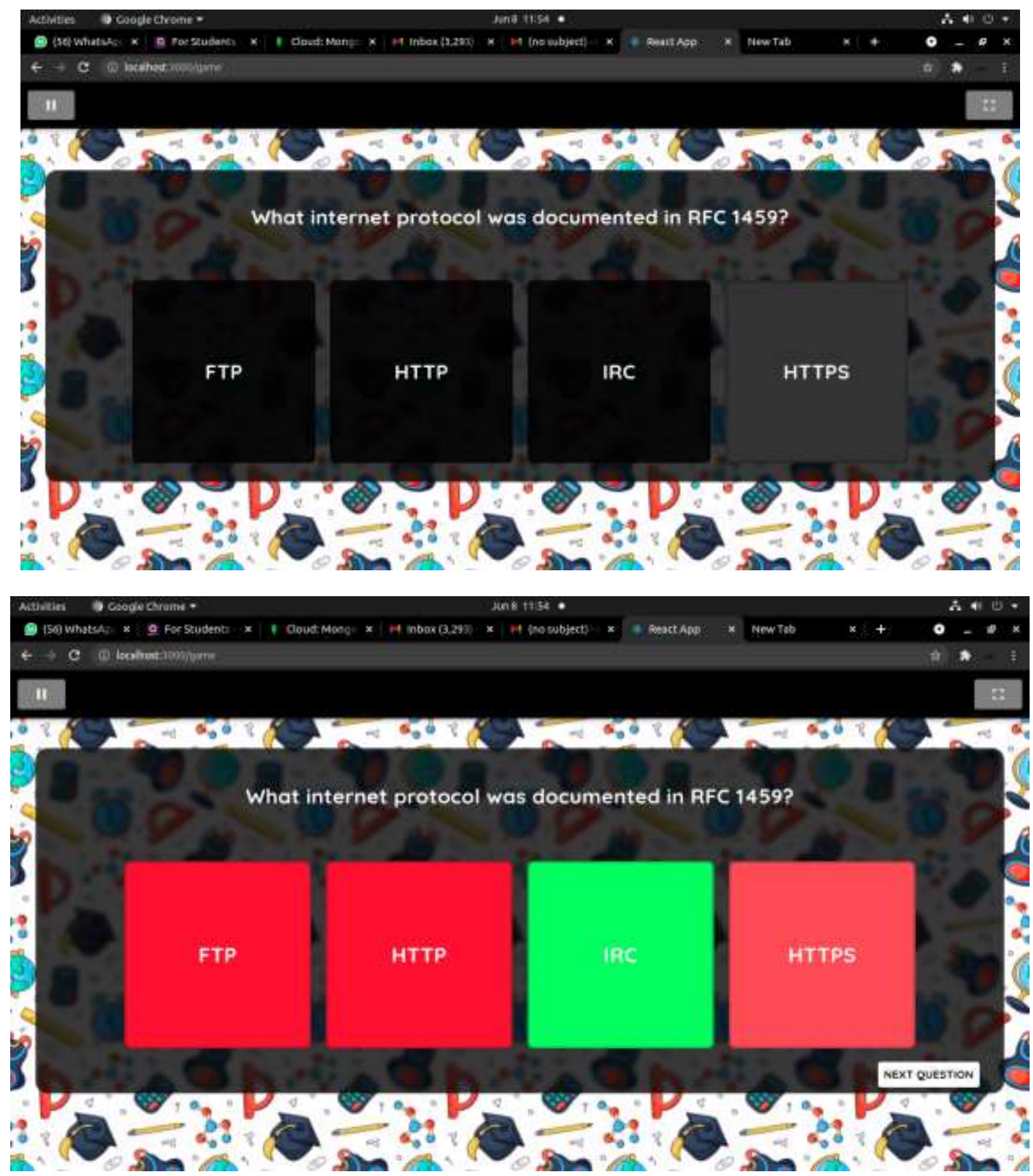

Fig . Question Model 
Fig. Result

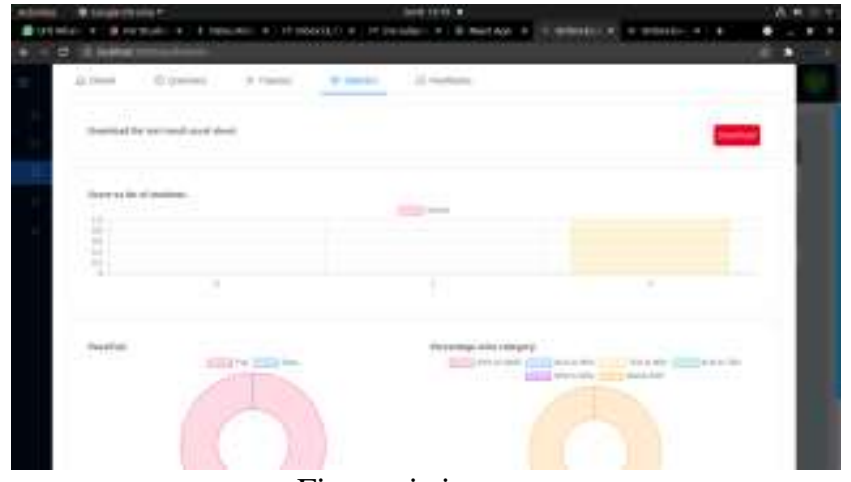

Fig. statistics page

\section{CONCLUSION}

The concepts presented describe how elements of the game can be integrated into evaluation components, in this case, gamification, based on evaluation for assessing candidates. Some simple educational computer games - crosswords, Sudoku, memory cards, treasure hunt etc. can be used in assessment \& self-assessment. These games are able to provide various educational actors such as students, teachers and administrators valid assessment information that will help the students as well as the teachers

\section{REFERENCES}

[1] J.C.C.Nunes, Menezes, R.D.Bortolli, "Potential of Gamification as Assessment https://www.scirp.org/journal/paperinformation.aspx?paperid =65415 2016.

[2] P. Souza, J. Mombach, F. Rossi and T. Ferreto, "GAMED: Gamification-Based Assessment Methodology for Final Project Development," 2019 IEEE 19th International Conference on Advanced Learning Technologies (ICALT), Maceio, Brazil, 2019, pp. 359-361, doi: 10.1109/ICALT.2019.00114.

[3] Koivisto, J., \& Hamari, J. (2014). Demographic Differences in Perceived Benefits from Gamification. Computers in Human Behavior, 35, $179-188$. http://dx.doi.org/10.1016/j.chb.2014.03.007

[4] Prensky, M. (2001). Digital Natives, Digital Immigrants Part 1. On the Horizon, 9, 1-6. http://dx.doi.org/10.1108/10748120110424816

[5] Gee, J. P. (2003). What Video Games Have to Teach us about Learning and Literacy? Computers in Entertainment (CIE), 1, 20-20. http://dx.doi.org/10.1145/950566.950595

[6] De-Marcos, L., Domínguez, A., Saenz-de-Navarrete, J., \& Pagés, C. (2014). An Empirical Study Comparing Gamification and Social Networking on E-Learning. 